\title{
A Study on Emotional Intelligence among Young Women in Hyderabad, India
}

\author{
Aprajita Raj $^{1 *}$, M. Sarada Devi ${ }^{1}$, P. Sreedevi ${ }^{1}$, R. Neela Rani ${ }^{2}$ and T. Supraja ${ }^{3}$ \\ ${ }^{1}$ Department of Human Development and Family Studies, ${ }^{3}$ Department of Food and Nutrition, \\ College of Community Science, Professor Jayashankar Telangana State Agricultural \\ University, Hyderabad, Telangana, India \\ ${ }^{2}$ AICRP-HSC, PG\&RC, Professor Jayashankar Telangana State Agricultural \\ University, Hyderabad, Telangana, India \\ *Corresponding author
}

\section{A B S T R A C T}

\begin{tabular}{|l|}
\hline K e y w o r d s \\
Self-awareness, \\
Emotional \\
Regulation, \\
Empathy, Social \\
skills, Self-esteem, \\
Emotional \\
Intelligence, \\
Stressful, Sevenfold \\
Emotional \\
Intelligence Scale \\
(SEIS) \\
\hline Article Info \\
\hline $\begin{array}{l}\text { Accepted: } \\
\text { 04 December } 2020 \\
\text { Available Online: } \\
\text { 10 January } 2021\end{array}$ \\
\hline
\end{tabular}

In the fast-paced competitive world young women faces problems that are related with various areas of life such as educational, social, familial and emotional. These problems have negative impact on their mental and emotional well-being. Emotional well-being of young adults is determined by various emotional intelligence skills such as self-awareness, emotional regulation, empathy, social skills, motivation and self-esteem. There are several researches conducted in the area of positive psychology which focus on the role of emotional intelligence and positive affect in the prevention of physical illness and mental disorders. Hence, the present study aimed to examine the emotional intelligence of young women. The samples were comprised of 120 young women in Hyderabad, India. Emotional intelligence was assessed through Sevenfold Emotional Intelligence Scale (SEIS) by Dr. Sarabjit Kaur (1999). Descriptive statistics such as frequencies and percentages were used for analysis of data. The results of the present investigation showed that majority of the young women had average, below average, low and extremely low levels of emotional intelligence whereas very few of them had above average level of emotional intelligence. The findings of the present research also revealed that none of the young women had high and extremely high level of emotional intelligence. This shows that women were lacking behind in emotional intelligence skills because of their overburdened life and stressful work and family life.

\section{Introduction}

Young women in the Indian society have been considered as inferior than men from ancient times yet women has explored and achieved what men does. Because of such type of inferiority, they have to face various issues and problems in their life. They have to go extra miles than men to prove themselves equivalent to men. Despite of many laws forcefully acted in favour of women, still women are facing many more problems in their daily life and struggling a lot to establish their career and family life. Some of the 
problems faced by the young women are because of their domestic responsibilities, cultural and social specified roles, etc. In today's society, young women have to juggle many roles at a time i.e., caregiver, homemaker, employee/ student, daughter, daughter-in-law, sister, friend, and multiple others. As demands increase to fulfill these roles, young women can feel overwhelmed with time pressures and unmet obligations. These pressures affect the emotional and mental well-being of young women and causes many psychological issues among them. Young women can become more productive and successful at work and home, and also acquire better psychosocial competencies with the development of emotional intelligence. This helps them to reduce stress by moderating conflict; promoting understanding and relationships; and fostering stability, continuity, harmony, love and spiritualty.

Emotional Intelligence is "the ability to perceive emotions, integrate emotions to facilitate thought understand emotions, and to regulate emotions to promote personal growth, (Mayer et al., 1999). It is the composite set of capabilities that enable a person to manage himself/herself and others" (Goleman, 1995, 1998). Emotional intelligence is core construct in today's Psychology. It is scientific understanding that emotional intelligence is key construct helpful for person to train their emotional skills as well as for living as more fulfilling and productive. Emotional intelligence has own importance due to management of emotions of person in modern society (Zeidner, Matthews and Roberts 2004). Therefore, an attempt was made to examine the emotional intelligence of urban young women in order to provide corrective measures/ training to enhance emotional intelligence skills for leading a productive and successful life.Several studies have been carried out to determine the emotional intelligence of young women.

Joyce and Magesh, (2017) conducted study among women employees working in IT sector by among 150 women. The results indicated that, the level of emotional intelligence among women employees working in IT sector is quite low.

Itziar et al., (2015) conducted a study on Emotional Intelligence, Life Satisfaction, and Psychological Well-Being in Graduates with a sample of 400 graduates age ranging from 22 to 60 years. The results of the study found that emotional intelligence shows a significant path through perceived stress to life satisfaction and psychological well-being even controlling for personality traits as variables. The research also suggests high emotional intelligence increases the wellbeing of the graduates by reducing the experience of stress.

Salehi (2015) studied the relationship between emotional intelligence and life satisfaction and the mediatory role of resiliency and emotional balance among the students of Zanjan University with a sample of 250 students. The results of the study indicated that there is a direct significant relationship between emotional intelligence and life satisfaction and between emotional balance and resiliency. Moreover, resiliency is positively significant with emotional balance and life satisfaction with life.

Tokpam et al., (2015) conducted study on emotional intelligence among 200 young working adults in Jorhat town. The results revealed that the mean score of male was higher than that of female respondents. The difference between male and female respondents in the level of emotional intelligence was found to be significant as the calculated value of $\mathrm{z}$ is 1.98 , which is greater 
than that of table value i.e. 1.96. It was observed that the male professionals had more capacities to perform the skills relating to emotional intelligence.

Karimi et al., (2013) conducted a study on the role of emotional intelligence and emotional labour on well-being and job-stress among community nurses. The study was investigated on the group of Australian community nurses in which emotional intelligence and emotional labour was related with the happiness and job stress. The study indicated that emotional intelligence plays a key role in the positive effects of job stress and further increasing the job retention of the workers.

The results found that emotional intelligence is positively correlated with the effects of the wellbeing and job stress of the nurses. Similarly, Bhatti (2013) using a sample of women who are employees of government and non-governmental organizations revealed that, women at both government and nongovernmental organizations have low levels of emotional intelligence.

Ahmad et al., (2009) investigated emotional Intelligence among male and female respondents. The research sample was comprised of one hundred and sixty subjects $(\mathrm{N}=160)$ who were categorized in two groups i.e., 80 males and 80 females. The result shows that males scored high than females on Emotional Quotient Inventory. High scores on this scale indicates the higher level of Emotional Intelligence, which clearly suggests that males are emotionally intelligent than females. A significant difference $(\mathrm{p}<$. 01), among males and females on emotional intelligence were found. Another Study conducted by Chu (2002) revealed that males have high level of emotional intelligence than that of females.
The main objectives of this study include to study the demographic profile of young women. To assess the level of various dimensions of emotional intelligence among young women. And also to assess the overall level of emotional intelligence among young women.

\section{Materials and Methods}

Based upon the nature of the research problem and objectives of the present study, Exploratory research design was opted for the study. Hyderabad from Telangana state was purposively chosen as the locale of the study because of convenience of the investigator to carry out the work in terms of time, effort and money. Koti women's college and Nizam college under Osmania university was purposively selected because of the availability and easy accessibility of the respondents. In this study, samples comprising of 120 young women under the age groups of 18-35 years i.e., 60 young women from each college were randomly selected. The interview schedule was designed to collect the socio demographic profile such as age, educational background, occupational status etc. The sevenfold emotional intelligence scale developed by Dr. Sarabjit Kaur was used for the present study. Frequencies and percentages, were used to analyze the collected data.

\section{Results and Discussion}

The study showed that an equal number of young women i.e. (33\%) constituted the total samples from the three age groups i.e., 18-23 years, 24-29 years and 30-35 years. An equal number of young women were selected from both colleges comprising of $33 \%$ for three age groups. More than half of the young women $(56 \%)$ were undergraduates and slightly less than half of the samples (44\%) were post graduates. Most of the sample 
(93\%) were students pursuing their graduation and post-graduation and very few $(7 \%)$ were engaged in contractual jobs. More than two third of the sample $(68 \%)$ were unmarried and nearly one-third $(32 \%)$ of the young women were married. Almost equal no. of samples i.e., $43 \%$ and $39 \%$ had $1-2$ and 3-4 siblings respectively followed by few samples $(18 \%)$ had 5 and above siblings. It also revealed that slightly more than half of the respondents (53\%) were second born followed by almost equal quarters of samples i.e., $24 \%$ and $23 \%$ were first born and later born respectively (Table 1-3).

\section{Self-awareness and appraisal}

The table 2 depicts the scores of young women in various components of emotional intelligence. In the component of 'Selfawareness and appraisal' more than two-third $(67 \%)$ of the respondents had moderate level followed by nearly one fourth of them $(28 \%)$ had low levels and a very meagre percent (5\%) had high levels in the respective category. Many of them were reported they had distorted/ negative view of their lives and others. This might be because their extreme emotions were triggered by something much more deeply rooted than the present events. They were unaware about their strengths and weaknesses which hinder their personal growth and success. It seems difficult for them to prioritize life goals and were having fear of vulnerability.

\section{Self-regulation and responsibility}

From table 2, it is observed that under selfregulation and responsibility more than two third $(69 \%)$ of the respondents were in moderate category, nearly one fourth of the respondents $(27 \%)$ belonged to low category and very few (4\%) had high levels respectively. Self-regulation and responsibility are the most important determining factors of emotional health. Less scores on self-regulation and responsibility domain refers that, young women had difficulty in managing their emotions and had tendency to get depressed/upset easily. They found it difficult to regulate their own feelings and as well as of others. They were unable to resist impulsive behaviours that might worsen their situation, and they often feel down. Among the limited opportunities and independence which young women experiences, there are challenges and faces difficult life events which tests their resilience. Inability to cope with those situations will lead to emotional instability and may give rise to suicidal tendencies.

\section{Self-motivation}

With respect to the component of 'Selfmotivation', nearly three-fourth $(70 \%)$ of the respondents had moderate levels followed by less than one fourth $(20 \%)$ had low levels and few $(10 \%)$ of them had high levels. This might be due to may not have had visionary thinking, and were egotistical and unwilling to admit when they are wrong. It also refers to low self-esteem, lack of faith in one's ability, fear of failure, lack of interest, fear of uncertainty, procrastination, laziness, stress and nervousness. Lack of motivation makes us apathetic and can stagnate life. Without motivation, people make compromises in life, settling for second best rather than striving for what they really want and ultimately limiting the level of true happiness they can achieve in their life.

\section{Self-esteem and confidence}

In the component of 'Self-esteem and confidence' more than two third of the young women $(68 \%)$ had moderate levels, nearly one fourth of them (28\%) had low levels and meagre percent (4\%) of them had high levels. This might be because they often feel 
unlovable, awkward, or incompetent. According to researchers Morris Rosenberg and Timothy J. Owens, who wrote Low SelfEsteem People: A Collective Portrait, people

with low self-esteem tend to be hypersensitive. They possess a fragile sense of self that can easily be wounded by others.

Table.1 General profile of the young women

\begin{tabular}{|c|c|c|c|c|c|c|c|}
\hline \multirow[t]{2}{*}{ S.No } & \multirow[t]{2}{*}{ Respondent Variables } & \multicolumn{2}{|c|}{$\begin{array}{l}\text { Koti Women's College } \\
(\mathrm{n}=60)\end{array}$} & \multicolumn{2}{|c|}{$\begin{array}{l}\text { Nizam College } \\
(\mathrm{n}=60)\end{array}$} & \multicolumn{2}{|c|}{ Total $(\mathrm{N}=120)$} \\
\hline & & $\mathbf{F}$ & $\mathbf{P}$ & $\mathbf{F}$ & $\mathbf{P}$ & $\mathbf{F}$ & $\mathbf{P}$ \\
\hline \multirow[t]{4}{*}{1.} & \multicolumn{7}{|l|}{ Age } \\
\hline & 18-23 Years & 20 & 33 & 20 & 33 & 40 & 33 \\
\hline & 24 - 29 Years & 20 & 34 & 20 & 33 & 40 & 34 \\
\hline & 30 - 35 Years & 20 & 33 & 20 & 33 & 40 & 33 \\
\hline \multirow[t]{3}{*}{2.} & \multicolumn{7}{|l|}{ Education } \\
\hline & Undergraduate & 36 & 60 & 31 & 52 & 67 & 56 \\
\hline & Post-Graduate & 24 & 40 & 29 & 48 & 53 & 44 \\
\hline \multirow[t]{3}{*}{3.} & \multicolumn{7}{|l|}{ Occupation } \\
\hline & Student & 57 & 95 & 55 & 92 & 112 & 93 \\
\hline & Other Job & 3 & 5 & 5 & 8 & 8 & 7 \\
\hline \multirow[t]{3}{*}{4.} & \multicolumn{7}{|l|}{ Marital Status } \\
\hline & Unmarried & 39 & 65 & 43 & 72 & 82 & 68 \\
\hline & Married & 21 & 35 & 17 & 28 & 38 & 32 \\
\hline \multirow[t]{4}{*}{5.} & \multicolumn{7}{|l|}{ Number of siblings } \\
\hline & $1-2$ & 29 & 48 & 23 & 38 & 52 & 43 \\
\hline & $3-4$ & 19 & 32 & 28 & 47 & 47 & 39 \\
\hline & 5 and above & 12 & 20 & 9 & 15 & 21 & 18 \\
\hline \multirow[t]{4}{*}{6.} & Ordinal position & & & & & & \\
\hline & First born & 19 & 31 & 10 & 17 & 29 & 24 \\
\hline & Second born & 25 & 42 & 38 & 63 & 63 & 53 \\
\hline & Later born & 16 & 27 & 12 & 20 & 28 & 23 \\
\hline
\end{tabular}

Note: ' $F$ ' represents frequency and ' $p$ ' represents percentage

Table.2 Distribution of young women based on the scores obtained on components of Emotional Intelligence $(\mathrm{N}=120)$

\begin{tabular}{|l|l|l|l|l|l|l|l|}
\hline S. No. & Components of EI & \multicolumn{4}{|l|}{ Levels of Emotional Intelligence } \\
\cline { 3 - 9 } & & Low & Moderate & High \\
\hline & & F & \% & F & $\%$ & F & $\%$ \\
\hline 1. & Self-awareness and appraisal & 34 & 28 & 80 & 67 & 6 & 5 \\
\hline 2. & Self-regulation and responsibility & 32 & 27 & 83 & 69 & 5 & 4 \\
\hline 3. & Self-motivation & 24 & 20 & 84 & 70 & 12 & 10 \\
\hline 4. & Self-esteem and confidence & 34 & 28 & 81 & 68 & 5 & 4 \\
\hline 5. & Empathy and acceptance of others & 31 & 26 & 84 & 70 & 5 & 4 \\
\hline 6. & Interpersonal relations & 31 & 26 & 83 & 69 & 6 & 5 \\
\hline 7. & Social skills & 25 & 21 & 89 & 74 & 6 & 5 \\
\hline
\end{tabular}

Note: 'F' represents frequency and 'P' represents percentage 
Table.3 Distribution of young women based on their level of Emotional Intelligence $(\mathrm{N}=120)$

\begin{tabular}{|l|l|l|l|}
\hline S. No. & $\begin{array}{l}\text { Level of Emotional } \\
\text { Intelligence }\end{array}$ & $\begin{array}{l}\text { Frequency } \\
\text { (F) }\end{array}$ & $\begin{array}{l}\text { Percentage } \\
(\mathbf{\%})\end{array}$ \\
\hline 1. & Extremely high & - & - \\
\hline $\mathbf{2 .}$ & High & - & - \\
\hline $\mathbf{3 .}$ & Above average & 8 & 7 \\
\hline $\mathbf{4 .}$ & Average/ Moderate & 46 & 38 \\
\hline $\mathbf{5 .}$ & Below average & 28 & 23 \\
\hline 6. & Low & 20 & 17 \\
\hline $\mathbf{7 .}$ & Extremely low & 18 & 15 \\
\hline
\end{tabular}

Note: ' $\mathrm{F}$ ' represents frequency and 'P' represents percentage

Fig.1 Level of Emotional Intelligence among young women

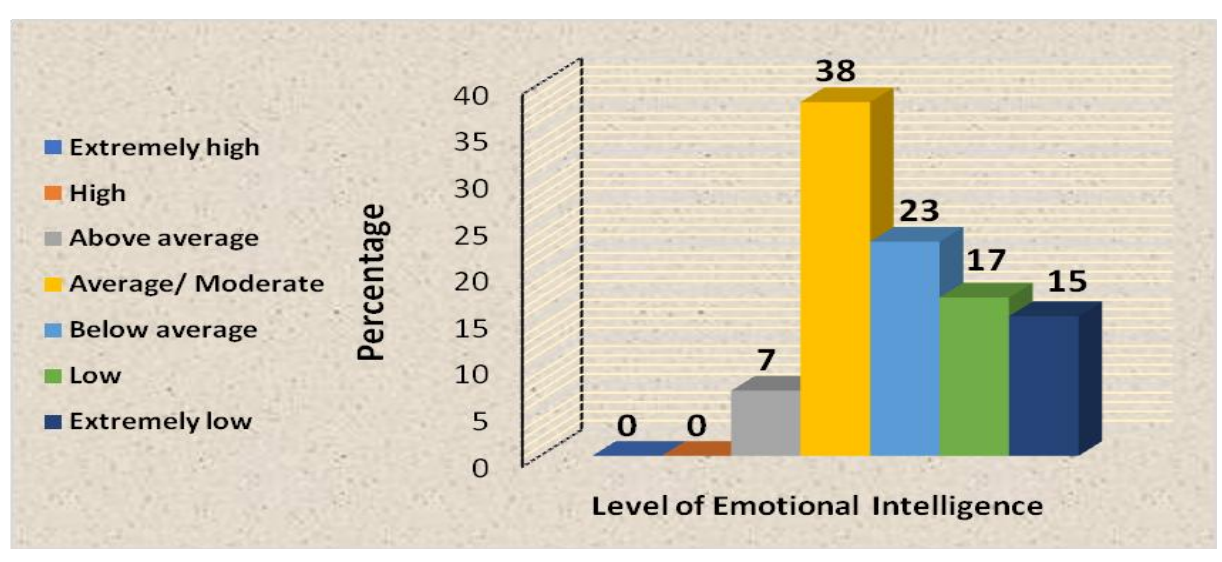

Having a negative perception of oneself can have serious consequences in their lives. They found it difficult to make their own choices and had tendency to follow along with what others are doing, saying, wearing, and going. This is because they were found to be especially prominent in the context of what others want or need.

\section{Empathy and acceptance of others}

With regard to the component of 'Empathy and acceptance of others', nearly three fourth of the respondents $(70 \%)$ had moderate levels, followed by almost one fourth of them (26\%) had scored low and meagre (4\%) had acquired high level in the respective domain. These less scores on empathy domains of EI indicated that young women were found to be behaviorally impulsive i.e. they made decisions based on emotional impulse, argumentative or always have to be "right", Quick in finding fault in others and can easily blame others for their own problems. They were also found to be insensitive to others needs. Empathy deficit leads to antisocial personality disorder and also comes out as source of personal conflicts of communication breakdown in intimate relationships and of adversarial attitudes - including hatred towards groups of people who differ in their beliefs, traditions or ways of life from your own.

\section{Interpersonal relations}


From the table 2 it was clearly depicted that more than two third of the respondents $(69 \%)$ scored moderate on interpersonal relations followed by nearly one fourth $(26 \%)$ of them had low levels and a very meagre percent $(5 \%)$ had high levels in the respective domain. This might be due to improper communication, inability to express their feelings, hiding and fighting over small issues and had tendency to not meet or interact with each other or avoid social gatherings. Interpersonal relationships are integral to meaning and fulfillment in our lives. Interpersonal difficulties can pose significant problems at home and work as a result of poor communication skills or conflict and can also negatively impact family relationships and building and maintaining close friendships. This can ultimately lead to isolation and depression.

\section{Social skills}

With respect to the 'Social skills', almost three fourth of the respondents (74\%) had moderate levels, followed by less than one fourth $(21 \%)$ of them had low levels and very few $(5 \%)$ had high levels respectively. Less scores on social skills depicted that young women experienced difficulties in interpersonal relationships with parents, teachers and peers. Poor social skills evoke highly negative responses from others that lead to high levels of peer rejection. Young women perceived that they were unable to make adjustments with various social circumstances and become intolerant towards people.

The figure 1 depicts the status of emotional intelligence among young women. More than one third $(38 \%)$ of the young women had moderate level and nearly quarter of them (23\%) had below average level of emotional intelligence. Almost equal percent of less than one fourth of young women had scored low
$(17 \%)$ and extremely low (15\%) levels on overall emotional intelligence respectively. It is important here to note that, none of the young women had 'high' and 'extremely high' levels of emotional intelligence before the life skill education offered. This might be because young women were found to be emotionally unstable, possess emotionally regressive behaviours like feeling inferior and were unable to handle/ manage their own emotions as well as of others. They had insecure and egoistic social maladjustments and personality disintegration behaviours. They were lacking in communication skills which creates relationship maladjustments and also perceived themselves as repressed or misguided towards their goals. The results were in congruence with the study published by (Ahmad et al.,2009; Tokpam etal.,2015; Joyce and Magesh, 2017) which revealed that women experienced more stress and were having low emotional intelligence when compared to male counterparts.

In conclusion the emotional intelligence plays crucial role in helping the young women to cope with dynamic change in the society. The skills involved in emotional intelligence are self-awareness, self-regulation, motivation, self-esteem, empathy, and social skills. Emotional intelligence impacts different aspects of our daily life, for instance, the way we behave and the way we interact with others. It also helps them to recognise own emotional state and the emotional states of others, and engage with people in a way that draws them to us. Emotional intelligence skills help in understanding of emotions to relate better to other people, form healthier relationships, achieve greater success at work, and lead a more fulfilling life. As the young women were overwhelmed with pressures and stress, they were more emotionally distressed which affects their emotional intelligence skills. In order to examine the emotional wellbeing among young women, emotional 
intelligence skills were assessed which will further help to provide corrective measures to enhance emotional intelligence among them. It was interesting to note that majority of the young women had average, below average, low and extremely low level of emotional intelligence. It is surprising to note that, none of the young women had high and extremely high level of emotional intelligence which clearly stated that young women were lacking behind in emotional intelligence skills. An intervention programme based on life skills needs to be carried out to elevate and to optimize the emotional intelligence among young women for leading a productive life.

\section{References}

Ahmad S, Bangash H and Khan A S. (2009). Emotional Intelligence and Gender Differences. Sarhad Journal of Agriculture; 25(1): 127-130.

Bhatti, A. G. (2013). An analysis of the general and gender difference regarding emotional intelligence among employees: evidence from government and nongovernment organizations of Hyderabad. KASBIT Business Journal; 6:106-113.

Chu, J. (2002). Boy's development. Reader's Digest. pp. 94-95.

Goleman, D. (1995). Emotional intelligence. New York: Bantam books.

Goleman, D. (1998). Working with emotional intelligence. New York: Bantam Books

Itizar U, Extremera N and Villa A. (2015). Emotional Intelligence, Life Satisfaction, and Psychological Well-
Being in Graduates: the Mediating Effect of Perceived Stress. Applied Research in Quality of Life; 11:12411252.

Joyce S. and Magesh R. (2017). A Study on Emotional Intelligence of Working Women. Indian Journal of Scientific Research; 14 (1): 248-251.

Karimi L, Leggat SG, Donohue L, Farrell G, Couper G E. (2013). Emotional rescue: the role of emotional intelligence and emotional labour on well-being and job-stress among community nurses. Journal of Advanced Nursing; 70(1):176-186.

Mayer J D, Caruso D R. and Salovey P. (1999). Emotional intelligence meets traditional standards for intelligence. Intelligence; 27(4): 267-298.

Salehi J. (2015). The relationship between emotional intelligence and life satisfaction and the mediatory role of resiliency and emotional balance among the students of Zanjan University. Acta Medica Mediterranea; 31(7): 1351-1357.

Tokpam R, Saikia J\& Borah T. (2015). Emotional Intelligence of Young Working Adults. International Journal of Current Research; 7(10): 21620-21622

Zeidner, M., Matthews, G. and Roberts, R. (2004). Emotional Intelligence in the Workplace: A Critical Review. Applied Psychology: An International Review, 53 (3): 371-99.

\section{How to cite this article:}

Aprajita Raj, M. Sarada Devi, P. Sreedevi, R. Neela Rani and Supraja, T. 2021. A Study on Emotional Intelligence among Young Women in Hyderabad, India. Int.J.Curr.Microbiol.App.Sci. 10(01): 251-258. doi: https://doi.org/10.20546/1jcmas.2021.1001.030 